\title{
Multifocal epithelioid glioblastoma mimicking cerebral metastasis: case report
}

\author{
J. Gasco*,**; B. Franklin*; G.N. Fuller***; P. Salinas* and S. Prabhu**
}

*Division of Neurosurgery, The University of Texas Medical Branch, Galveston. Texas. **Departments of Neurosurgery and ***Pathology, The University of Texas M. D. Anderson Cancer Center, Houston, Texas.

\section{Summary}

Objective. Epithelioid glioblastoma is a rare morphologic subtype of glioblastoma that closely mimics metastatic carcinoma or metastatic melanoma histologically. All previous case reports of this unusual glioblastoma variant have been solitary lesions. We report here the first case to our knowledge of multifocal epithelioid glioblastoma mimicking cerebral metastasis.

Clinical presentation. A 67-year-old man with a prior history of mycosis fungoides, a common form of cutaneous T-cell lymphoma, presented with memory loss and impaired peripheral vision. Two discrete brain lesions highly suspicious for metastases were identified by magnetic resonance imaging (MRI).

Intervention. The patient underwent two separate craniotomies; both lesions were successfully resected in toto with an excellent post-surgical outcome.

Conclusion. Epithelioid glioblastoma is one of the rarest morphologic subtypes of glioblastoma. Here we describe the first case to our knowledge of multifocal epithelioid glioblastoma that convincingly mimicked a secondary metastatic process. Multifocal epithelioid glioblastoma should be included in the differential diagnosis of patients who present with multiple discrete brain lesions. An attempt at gross total resection is recommended when anatomically feasible for definitive histopathological diagnosis and to improve progression free survival of patients who present with similarly ambiguous and potentially misleading multiple lesions.

KEY WORDS: Epithelioid glioblastoma. Immunohistochemistry. Neoplasm. Metastasis.

Glioblastoma epiteloide multifocal simulando metástasis cerebrales. Presentación de un caso

Recibido: 1-11-08. Aceptado:26-08-09
Resumen

Objetivo. El glioblastoma epiteloide es un subtipo morfológico poco común del glioblastoma que puede imitar al carcinoma o melanoma metastásico histológicamente. Todos los casos reportados de esta variante inusual de glioblastoma han sido lesiones solitarias. Presentamos el primer caso de glioblastoma multifocal epiteloide imitando metástasis cerebral.

Presentación clínica. Varón de 67 años con historia previa de micosis fungoide, una forma común de linfoma cutáneo de células $T$, cuyos síntomas fueron pérdida de memoria y alteraciones del campo visual periférico. Dos lesiones sospechosas de metástasis fueron identificadas por resonancia magnética.

Intervención. Mediante dos craneotomías independientes, ambas lesiones se resecaron in toto con buen resultado post-quirúrgico.

Conclusión. El glioblastoma epiteloide es uno de los subtipos morfológicos mas raros de glioblastoma. Los autores describen aquí el primer caso de glioblastoma epiteloide multifocal con apariencia de metástasis secundaria. Este diagnóstico debe ser incluido en el diferencial de pacientes con lesiones multifocales. El intento de resección total se recomienda cuando éste sea viable para obtener un diagnóstico definitivo así como para mejorar la supervivencia libre de enfermedad en pacientes cuya presentación incluya lesiones múltiples que puedan dirigir a un tratamiento inadecuado.

PALABRAS CLAVE: Glioblastoma epiteloide. Inmunohistoquímica. Neoplasia. Metástasis.

Introduction

Epithelioid glioblastoma is a rare morphological subtype of glioblastoma ${ }^{5,8,15,16}$. It has not yet been formally codified in the World Health Organization (WHO) Classification of Tumours of the Central Nervous System ${ }^{9}$. This glioblastoma variant can cause diagnostic confusion on several levels, including on preoperative imaging evalua- 

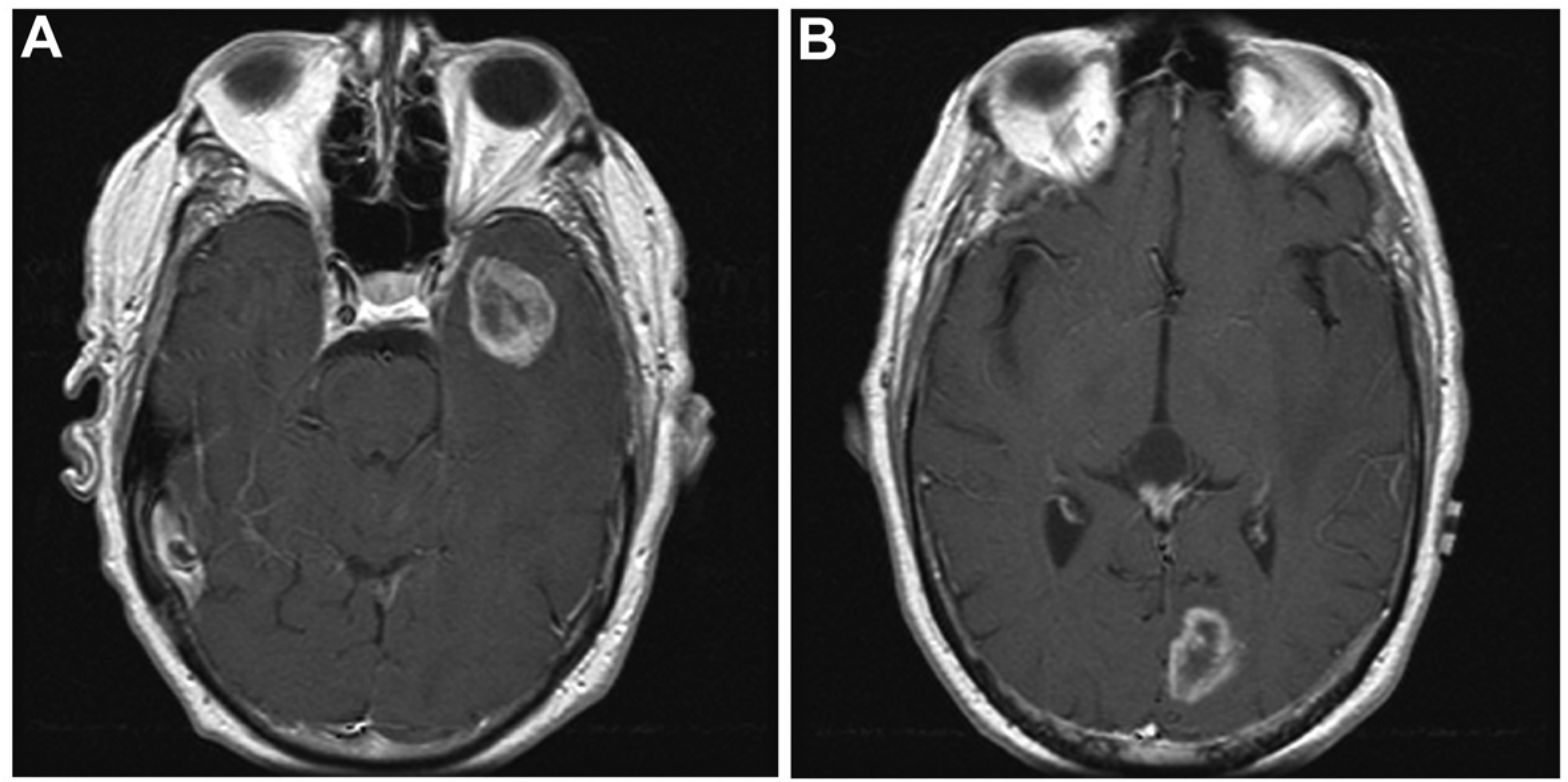

Figure 1. A: preoperative gadolinium-enhanced T1-weighted axial MRI scan revealing a dominant lesion located in the left temporal lobe, demonstrating ring enhancement. B: preoperative gadolinium-enhanced T1-weighted axial MRI scan revealing a second smaller lesion located in the left occipital lobe, also demonstrating ring enhancement.

tion and on histopathologic examination. It closely mimics metastatic epithelioid carcinoma or amelanotic metastatic melanoma histologically. On imaging studies, many examples are superficial and well-circumscribed, mimicking metastatic carcinoma or meningioma. The potential for misinterpretation of the imaging studies and the histopathology is even more likely when this high-grade glioma presents as multifocal disease.

\section{Case report}

A 67-year-old, right-handed man with a past medical history significant for mycosis fungoides, a form of cutaneous T-cell lymphoma, was referred to the University of Texas M. D. Anderson Cancer Center after presenting with acute onset memory loss, difficulty finding words, and impaired peripheral vision. The patient denied any associated seizure activity or confusion. Initial brain computed tomography (CT) and MRI scans revealed two discrete brain lesions - one dominant lesion located in the left temporal lobe, and a second smaller lesion located in the left occipital lobe (Fig 1A and 1B). The neurological examination was significant for speech hesitancy, suggestive of a mild expressive aphasia, and right-sided homonymous hemianopsia on visual field testing. No other focal neurological deficits were apparent. An extensive metastatic workup failed to reveal evidence of systemic malignancy.

As an adjunct to definitive therapy, the patient received high-dose dexamethasone and experienced marked improvement of his symptoms. Two ipsilateral craniotomies were performed in a single intervention assisted by neuronavigation and ultrasonography. Intraoperatively, both lesions appeared well circumscribed and gross total resection of both was successfully achieved.

Histopathological examination revealed a high-grade epithelioid neoplasm comprised of variably-sized cells with abundant eosinophilic cytoplasm, rounded cell contours without fibrillary cytoplasmic processes, and nuclei that frequently displayed prominent single macronucleoli (Fig. 2A). The morphologic features were compatible with either metastatic epithelioid carcinoma or metastatic amelanotic melanoma. Subsequent immunohistochemical studies revealed lack of reactivity for both carcinoma markers (cytokeratins) and melanoma markers (HMB-45). Based on these negative results for metastatic neoplasm, additional immunohistochemical studies were then performed, which revealed strong cytoplasmic positivity for glial fibrillary acidic protein (GFAP; Fig. 2B) and S-100 protein. The morphologic features combined with the immunophenotypic profile confirmed a histopathologic diagnosis of epithelioid glioblastoma, and, in conjunction with the preoperative imaging studies, a clinical diagnosis of multifocal epithelioid glioblastoma was rendered.

The patient had an uncomplicated postoperative course and was discharged from the hospital on postoperative day three without any neurological deficits. Postoperative MR imaging confirmed resection of the two contrast-enhancing lesions. The patient received adjuvant chemotherapy with low-dose temozolomide. Sixty Gray (Gy) in 30 fractions of intensity-modulated radiation therapy (IMRT) was deli- 


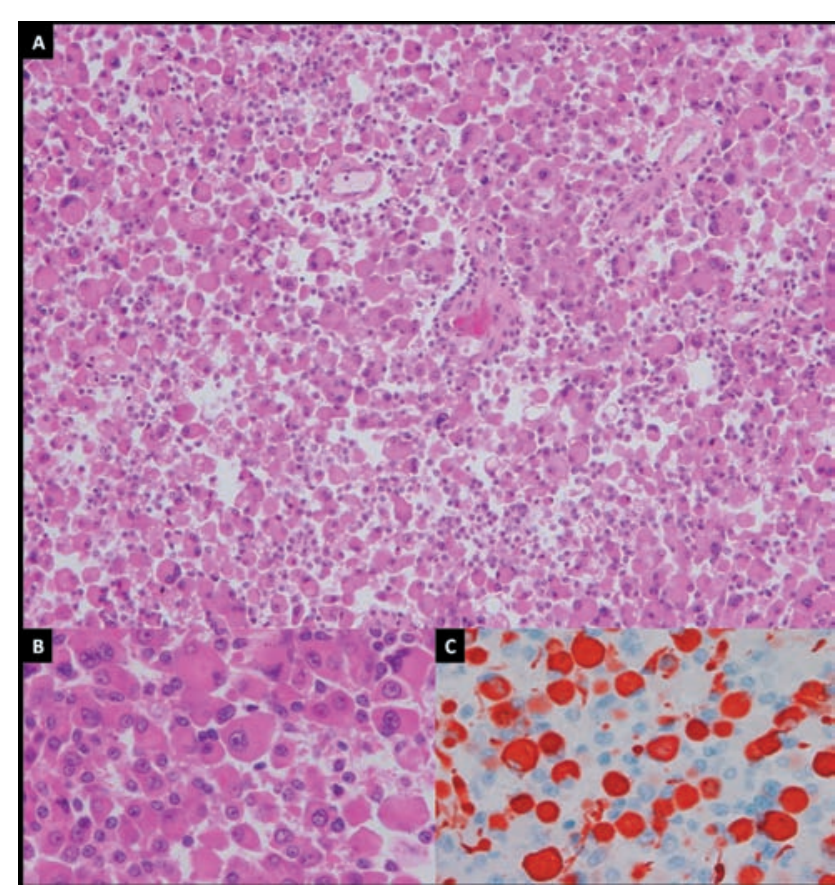

Figure 2. A: Histologic section demonstrating a high-grade epithelioid neoplasm (H\&E, x40). B: Histologic section in higher magnification (H\&E, x400). C: Histiologic section showing strong cytoplasmic positivity for GFAP in a subset of tumor cells, confirming a diagnosis of epithelioid glioblastoma (GFAP immunoperoxidase with hematoxylin counterstain, $x 400)$.

vered to the resection cavity; and 48 Gy in equivalent fractions was delivered to the surrounding brain parenchyma.

\section{Discussion}

Glioblastoma is remarkable for the diversity of morphological appearances that the constituent tumor cells can assume. In some tumors, a distinctive cell type may predominate, comprising $50 \%$ or more of the tumor. Two of the more common examples are small cell glioblastoma and giant cell glioblastoma ${ }^{9}$. Rarer forms include granular cell glioblastoma ${ }^{17}$, rhabdoid glioblastoma ${ }^{6}$, and signet-ring cell glioblastoma ${ }^{10}$. Of the various morphologic patterns that may be seen, epithelial differentiation is among the rarest, accounting for only $1.6 \%$ of all glioblastoma cases in one large series ${ }^{15}$. The various forms of epithelial differentiation in glioblastoma can be divided into pseudoepithelial patterns (adenoid and epithelioid) and true epithelial differentiation ${ }^{15}$. True epithelial differentiation is characterized not only by epithelial morphology but also by the expression of tissue-specific epithelial markers, such as epithelial membrane antigen (EMA), low-molecular weight keratins (e.g., CAM5.2), and carcinoembryonic antigen (CEA). In contrast, pseudoepithelial differentiation consists only of

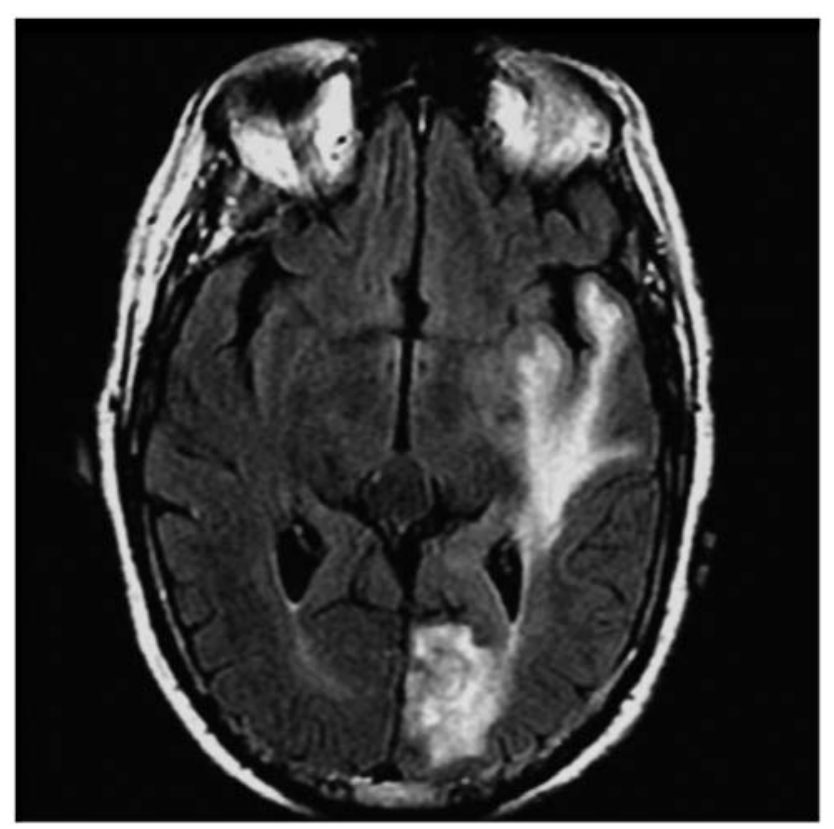

Figure 3. MRI T2-FLAIR image demonstrating hyperintense signal changes connecting the left temporal and left occipital lesions.

epithelial-like morphology, without expression of specific epithelial antigens; rather, the tumor cells forming the epithelial-like structures are usually at least partially reactive for glial markers (GFAP and S-100 protein). It should be noted in passing that cross-reactivity to broad spectrum cytokeratins, in particular cytokeratins AE1/AE3, is frequently seen in glioblastoma in general regardless of morphologic subtype and this well-recognized phenomenon does not constitute evidence of epithelial differentiation ${ }^{13}$.

True epithelial differentiation can assume the form of either squamous cell nests or glandular nests ${ }^{11,15}$. Pseudoepithelial differentiation has two different forms: adenoid, with cohesive cell clusters arranged in cords, nests and/or a cribriform pattern, and epithelioid, in which the tumor cells are relatively large, round, have copious amounts of eosinophilic cytoplasm, generally lack cytoplasmic processes or are very process-poor, and often display large nuclei with single prominent nucleoli $1^{1,4,5,8,12,15}$. Of these three major types of epithelial morphology, adenoid is the most common, followed by true epithelial differentiation, and with epithelioid glioblastoma being the rarest $\mathrm{t}^{15}$. Sarcomatous metaplasia (gliosarcoma) is commonly seen in association with epithelial morphology, especially in adenoid glioblastoma, in which it is present in over $50 \%$ of cases ${ }^{15}$.

All forms of pseudoepithelial and true epithelial differentiation can be mistaken for metastatic carcinoma. Because the adenoid and true epithelial differentiation forms also typically have a more typical glial component, they may be mistaken for either a tumor-to-tumor metas- 
tasis or a collision tumor ${ }^{12}$. Epithelioid glioblastoma, in contrast, can be mistaken for metastatic epithelioid carcinoma or for metastatic amelanotic melanoma ${ }^{5}$. Some examples of epithelioid glioblastoma exhibit variable degrees of cytoplasmic lipid vacuoles, with this change prominently affecting a majority of tumor cells in about $10 \%$ of cases; such tumors have been referred to as "lipidized epithelioid glioblastoma"15,16. Preliminary molecular genetic characterization of the three forms of glioblastoma with epithelial morphology has been performed ${ }^{15}$. The results show that most alterations are similar to those found in glioblastoma in general. Among the three forms, epithelioid glioblastoma is notable for the high percentage of cases exhibiting EGFR gene amplification $(50 \%)$ and strong EGFR immunopositivity (63\%), compared to only $20 \%$ of adenoid glioblastomas and glioblastomas with true epithelial differentiation ${ }^{15}$.

The occurrence of multiple foci of glioblastoma has long been recognized and such instances have traditionally been categorized as either multifocal or multicentric, with multifocal glioblastoma exhibiting an obvious pathway of spread, such as through commissural pathways like the corpus callosum, fornix or massa intermedia, or by dissemination via the cerebrospinal pathways, and multicentric glioblastoma comprising truly independent, separate foci of gliomagenesis ${ }^{2,3}$. Multifocal glioblastoma is monoclonal in origin, whereas multicentric glioblastoma would be postulated to arise from two separate clones. In practice, the imaging demonstration of a direct connection between two glioma epicenters in the form of T2-weighted or T2FLAIR signal hyperintensity, as is seen in the present case, is taken as presumptive evidence of direct contiguous spread between the foci, and such cases are considered to be multifocal glioblastoma even in the absence of histologic or molecular genetic confirmation.

The diagnostic pitfall of multifocal or multicentric glioblastoma mimicking metastatic disease is well recognized $^{3,14}$. This potential for misinterpretation is even more likely for epithelioid glioblastoma because of its tendency to be relatively well-circumscribed and superficially located in the vicinity of the gray-white matter junction. In the present case, the patient's history of mycosis fungoides posed an additional complicating factor as mycosis fungoides involvement of the brain, although rare, is very well recognized $^{7,18}$.

\section{Conclusion}

Epithelioid glioblastoma is a very rare, but well documented, entity. Here we describe a case of multifocal epithelioid glioblastoma that convincingly mimicked a secondary metastatic process both on preoperative imaging studies and on histopathology. Multifocal epithelioid glioblastoma should be considered in the differential diagnosis of all patients who present with multiple brain lesions, even in the presence of a known primary systemic malignancy. An attempt at gross total resection is recommended for definitive histopathologic diagnosis and to improve progression free survival of patients presenting with similarly ambiguous and potentially misleading multiple lesions.

\section{References}

1. Akimoto, J., Namatame, H., Haraoka, J., Kudo, M.: Epithelioid glioblastoma: a case report. Brain tumor pathology 2005; 22: 21-27.

2. Batzdorf, U., Malamud, N.: The problem of multicentric gliomas. Surg Neurol 1963; 20: 122-136.

3. Chadduck, W.M., Roycroft, D., Brown, M.W.: Multicentric glioma as a cause of multiple cerebral lesions. Neurosurgery $1983 ; 13: 170175$.

4. du Plessis, D.G., Rutherfoord, G.S., Joyce, K.A., Walker, C.: Phenotypic and genotypic characterization of glioblastoma multiforme with epithelial differentiation and adenoid formations. Clinical neuropathology 2004; 23: 141-148.

5. Fuller, G.N., Goodman, J.C., Vogel, H., Ghorbani, R.: Epithelioid glioblastoma: a distinctive clinicopathologic entity [abstract]. J Neuropathol Exp Neurol 1998; 57: 501.

6. Fung, K.M., Perry, A., Payner, T.D., Shan, Y.: Rhabdoid glioblastoma in an adult. Pathology 2004; 36: 585-586.

7. Grevelink, S.A., Fuller, G.N., Olsen, E.A.: Central nervous system involvement by cutaneous $\mathrm{T}$ cell lymphoma. J Am Acad Dermatol 1991; 25: 542-549.

8. Kleinschmidt-DeMasters, B.K., Meltesen, L., McGavran, L., Lillelei, K.O.: Characterization of glioblastomas in young adults. Brain Pathol 2006; 16: 273-286.

9. Louis, D.N., Ohgaki, H., Wiestler, O.D., Cavenee, W.K., Burger, P.C., Jouvet, A., Scheithauer, B.W., Kleihues, P.: The 2007 WHO classification of tumours of the central nervous system. Acta neuropathologica 2007; 114: 97-109.

10. Martin, S., Bonnin, J., Hall, D., Hattab, E.: Glioblastoma with signet-ring morphology: a case report and review of the literature [abstract]. J Neuropathol Exp Neurol 2009; 68: 582.

11. Mork, S.J., Rubinstein, L.J., Kepes, J.J., Perentes, E., Uphoff, D.F.: Patterns of epithelial metaplasia in malignant gliomas. II. Squamous differentiation of epithelial-like formations in gliosarcomas and glioblastomas. Journal of neuropathology and experimental neurology 1988; 47: 101-118.

12. Mueller, W., Lass, U., Herms, J., Kuchelmeister, K., Bergmann, M., von Deimling, A.: Clonal analysis in glioblastoma with epithelial differentiation. Brain pathology (Zurich, Switzerland) 2001; 11:39-43.

13. Oh, D., Prayson, R.A.: Evaluation of epithelial and keratin markers in glioblastoma multiforme: an immunohistochemical study. Archives of pathology \& laboratory medicine 
1999; 123: 917-920.

14. Prather, J.L., Long, J.M., van Heertum, R., Hardman, $\mathrm{J}$.: Multicentric and isolated multifocal glioblastoma multiforme simulating metastatic disease. Br J Radiol 1975; 48: $10-15$

15. Rodriguez, F.J., Scheithauer, B.W., Giannini, C., Bryant, S.C., Jenkins, R.B.: Epithelial and pseudoepithelial differentiation in glioblastoma and gliosarcoma. Cancer 2008; 113: 2779-2789.

16. Rosenblum, M.K., Erlandson, R.A., Budzilovich, G.N.: The lipid-rich epithelioid glioblastoma. Am J Surg Pathol 1991; 15: 925-934.

17. Shi, Y., Morgenstern, N.: Granular cell astrocytoma.
Arch Pathol Lab Med 2008; 132: 1946-1950.

18. Vu, B.A., Duvic, M.: Central nervous system involvement in patients with mycosis fungoides and cutaneous largecell transformation. J Am Acad Dermatol 2008; 59: S16-S22.

Gasco, J.; Franklin, B.; Fuller, G.N.; Salinas, P.; Prabhu, S.: Multifocal epithelioid glioblastoma mimicking cerebral metastasis: case report. Neurocirugía 2009; 20: 550-554.

Corresponding author: Jaime Gasco, MD. The University of Texas Medical Branch. Division of Neurosurgery. 301 University Boulevard. Galveston, Texas 77555- 0517

Email: jagascot@utmb.edu 